Noname manuscript No.

(will be inserted by the editor)

\title{
Experimental study of the dynamic flexural strength of concrete
}

\author{
Xavier Régal • Jean-Luc Hanus
}

Received: date / Accepted: date

\begin{abstract}
In this paper, we analyze the increase in the dynamic flexural strength of concrete according to strain rate. A simple beam with center-point loading and a classical electro-mechanical testing machine are used to determine the static flexural strength. The dynamic ones are carried out with the split Hopkinson pressure bars (SHPB) device in the same three-point bending configuration. The outer faces of the beams are instrumented with strain gauges to record the extreme tensile strains. Moreover, full-field displacement measurements are obtained using Digital Image Correlation (DIC) on images recorded by a very high-speed camera. Strain gauges and DIC measurements are compared and used to determine the onset of failure and to evaluate the rate-related tensile strength. Several tests are performed at strain rates in the range from $1 / \mathrm{s}$ to $15 / \mathrm{s}$. As expected, a significant increase of the flexural ten-

Xavier Régal · Jean-Luc Hanus $(\bowtie)$

INSA Centre Val de Loire, Université d'Orléans, laboratoire PRISME, EA 4229

88 boulevard Lahitolle, 18020 Bourges Cedex, France

Tel.: +33 (0)2 48484047

E-mail: jean-luc.hanus@insa-cvl.fr
\end{abstract}


sile strength with strain-rate is observed in accordance with results from the literature.

Keywords Concrete $\cdot$ Strain rate effect · Dynamic Increase Factor · Digital Image Correlation $\cdot$ Flexural strength $\cdot$ Split Hopkinson Pressure Bar

\section{Introduction}

Most structural materials used by the civil engineer may be subjected to abnormal accidental loads such as impact or blast loading. During such severe impulsive loading, high strain rates are imposed on the structures. In order to accurately simulate and predict the response of structures or to assess their performance, a thorough quantification of the strain rate sensitivity is required. Due to the difficulty to perform and analyze dynamic experiments under various multi-axial states of stress, most of the available literature refer to uniaxial compression and tension tests. The increase in material strength under dynamic loading is usually modeled with a Dynamic Increase Factor (DIF) defined as the ratio of dynamic to static strength. This, materials' properties dependency on strain rate is easily applicable to engineering design and analysis of concrete structures against dynamic loadings (DoD 2008). Design values for DIF are given in tables but a more accurate estimate of the DIF is usually obtained with DIF design curves such as CEB recommendation (CEB 1988) or (Malvar and Crawford 1998) review. These empirical curves are based on a fitting of the available dynamic experimental results. All test data show a similar trend, the curve is a bilinear function of the strain rate in a log- 
$\log$ plot. The slope change occurs between $1 \mathrm{~s}^{-1}$ and $30 \mathrm{~s}^{-1}$ for concrete in tension. A large part of the available results in tension is compiled in Figure 1.

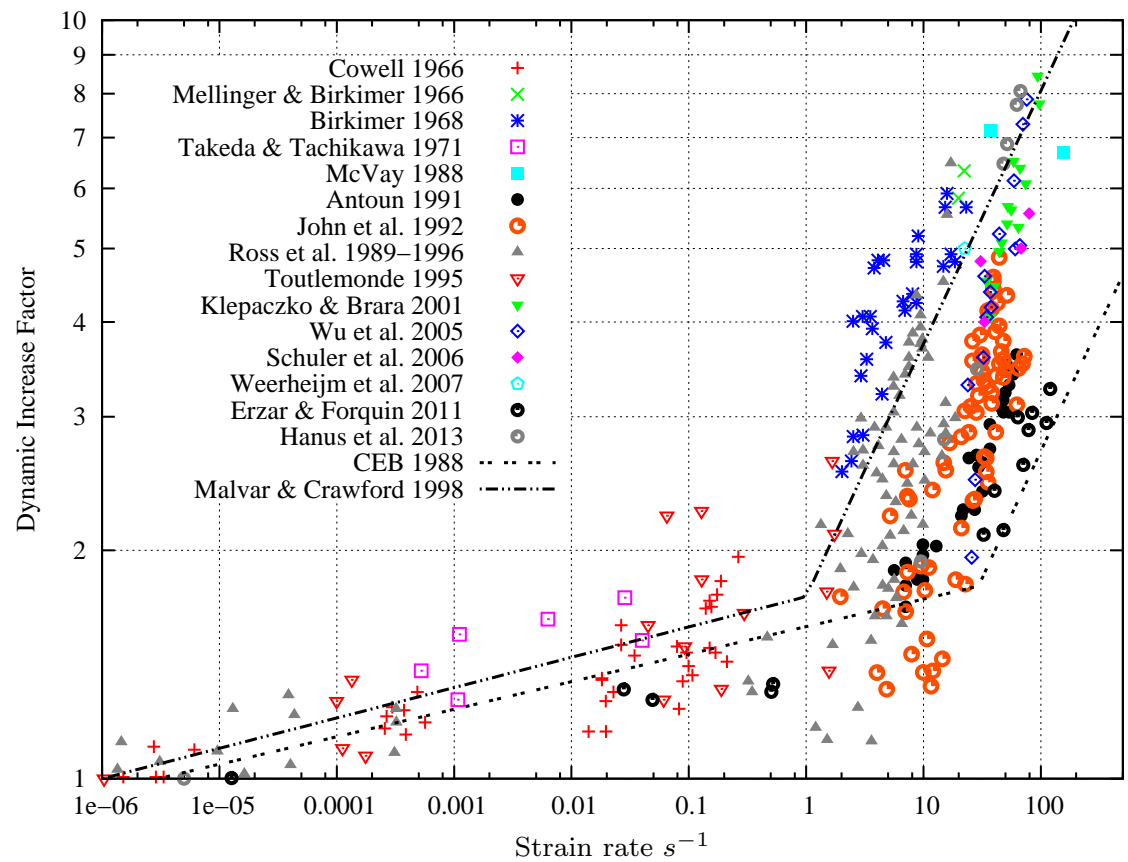

Fig. 1: Strain rate influence on tensile strength

Since the critical review of (Bischoff and Perry 1991) and after an intense debate, it is now well established that the apparent increase in the compressive strength is only partially due to a material effect - the free water effect - but also to a structural one - lateral inertia confinement. For tensile loading, the presence of free water is also put forward to explain the rate dependency at low strain rate $\left(\dot{\varepsilon}<1 \mathrm{~s}^{-1}\right)$ (Rossi and Toutlemonde 1996). However for higher strain rates, where the rate effect is apparently more pronounced in tension 
than in compression, the matter is not free from doubt and needs more studies.

As observed in Figure 1, there is significant scatter from the results which can be partly attributed to the specimen micro-structure, shape and size but also to the testing and post-processing methods. Indeed, quasi-static and dynamic strength may not refer to the same configuration. For the evaluation of the tensile strength of brittle materials under quasi-static loading, the direct tension testing, which requires a very rigorous testing procedure involving an extensive specimen preparation, is rarely performed. Instead, two standardized indirect tests such as splitting tests or flexural tests are preferentially used to measure this property, following international standards (ISO 1920-4)․․

In dynamic experiments, at low to moderate strain rates, usually obtained with a high speed hydraulic machine, the same configurations are encountered $\left(\dot{\varepsilon}<1 \mathrm{~s}^{-1}\right)$. Even if direct tensile tests and splitting tests can be performed with Split Hopkinson Pressure Bar (Tedesco et al 1989), (Tedesco et al 1991), in the high speed regime, spalling tests is the most widespread method. This technique consists in using impact compressive loading to produce impact tensile loading to the specimen when the pulse reflects on the back free surface of the specimen. Due to extensive developments, an experimental setup derived from SHPB technique has been widely employed to investigate the spalling fracture of concrete (Daimaruya and Kobayashi 2000), (Klepaczko and Brara

1 This standard is equivalent to the European EN 12390-5 and to the American ASMT C293. 
2001), (Wu et al 2005), (Schuler et al 2006), (Weerheijm and Van Doormaal 2007), (Erzar and Forquin 2010).

The SHPB flexural test is a convenient alternative, consistent with the standard static one, to evaluate the strain rate dependency of the tensile strength. It has been more extensively employed in SHPB dynamic fracture toughness testing than other configurations (Jiang and Vecchio 2009) on various brittle materials, such as geomaterials (Zhang and Zhao 2013), ceramics (Pittari III et al 2015) and polymers (Huang S. et al 2009). The three bars/threepoint bending configuration has been initially proposed and developed for determining the dynamic fracture-initiation toughness (Yokoyama and Kishida 1989). This technique has been less frequently applied to un-notched specimen. Among the few applications, we can notice applications to very thin brick specimen (Delvare et al 2010), advanced ceramics (Belenky and Rittel 2011), aluminum bars (Pierron et al 2011) or to normalized concrete specimen (Hanus et al 2012). Concerning these works, it is worth mentioning that inertial effects play a prominent role and must be taken into account for accurate processing of the test data as discussed in the sequel.

The aim of the present research is to apply this method to study the evolution of the flexural strength in the intermediate strain rate between $1 s^{-1}$ to $30 s^{-1}$, where the slope change is supposed to occur (Fig. 1). Unlike previous studies, (Delvare et al 2010) and (Hanus et al 2012), where the pressure bars were made of aluminum, in the new experiments, nylon pressure bars are used 
and the instrumentation is accompanied by high-speed imaging. At this stage, one should note that recent progress in camera-based computer vision techniques allow to capture dynamic sequences and access full-field measurements thanks to video post-processing. In a three-point bending impact test, (Pierron et al 2011) the full-field measurements, obtained using high-speed camera, were used to reconstruct the impact force with the Virtual Fields Method (VFM). Concerning brittle materials, it remains challenging to use these techniques because rupture occurs at very low displacements and strains and the time to failure is very short. These two conditions lead to conflicting requirements of simultaneous high resolution and high recording frequency. Some Brazilian tests have been conducted on marble by (Zhang and Zhao 2013) where Digital Image Correlation (DIC) measurements were found to give satisfactorily results in comparison with strain gauges measurements. The VFM has also been applied to full-field measurements on spalling experiments by (Pierron and Forquin 2012) allowing the identification of Young's modulus during the tests and the construction of local sress-strain curves. (Forquin 2012) used an ultra high-speed camera with the DIC method to characterize the crack velocity in concrete. In our experiments, the displacement and strain fields are also obtained at the surface of the specimen thanks to the DIC. These new data are used to improve post-processing, that was previously based only on strain gauges measurements.

In the following sections, first the material and DIC set-up are presented. Next, the static experimental details and post-processing procedures are de- 
scribed and the results presented. In turn, the dynamic experimental details and post-processing procedures are described and the results presented. Then, the synthesis of static and dynamic results is used to evaluate the strain rate effect on the DIF. In a last part, the crack patterns are examined. Finally, some concluding remarks are drawn.

\section{Material and DIC set-up}

2.1 Material and specimen preparation

A common concrete, named R30A7, has been used to cast the specimen. This concrete has a $30 \mathrm{MPa} 28$-day compressive strength and a slump of $7 \mathrm{~cm}$ characterizing concrete consistency ${ }^{2}$. In order to ensure a minimum variability in the mechanical properties of the concrete, a rigorous manufacturing procedure has been developed and a very high-quality cement is used (Gabet et al 2008). The maximum aggregate size is $8 \mathrm{~mm}$ (Table 1 ).

Table 1: Concrete mix proportions (Gabet et al 2008)

\begin{tabular}{l|r} 
Constituent & Mass per $1 \mathrm{~m}^{3}$ \\
\hline Water & $169 \mathrm{~kg}$ \\
Sand D $1800 \mu \mathrm{m}$ & $838 \mathrm{~kg}$ \\
Aggregates BB 0.5/8 & $1007 \mathrm{~kg}$ \\
Cement : CEM 52.5 N PM ES CP2 & $263 \mathrm{~kg}$ \\
Density & $2277 \mathrm{~kg} / \mathrm{m}^{3}$ \\
\hline
\end{tabular}

The concrete is cast in prismatic moulds conforming to the international standard (ISO 1920-3) ${ }^{3}$ width $e=40 \mathrm{~mm}$, height $h=40 \mathrm{~mm}$ and length

\footnotetext{
2 ISO 1920-2, Testing of concrete Part 2: Properties of fresh concrete

3 ISO 1920-3, Testing of concrete Part 3: Making and curing test specimens
} 
$L=160 \mathrm{~mm}$. After 28 days in a saturated environment, the specimens are immersed in water until saturation and then placed in a drying oven until weight stabilization.

The natural texture and contrast of the specimens are not sufficient to allow DIC measurements of small displacements. As a consequence, a random spray-painted speckle pattern made of black spots on a white background is applied on the specimen's front surface prior to testing.

\subsection{Digital Image Correlation}

The DIC is a contact-less powerful tool which provides a full-field measurement of the displacements on the surface of the object of interest, thanks to the images acquired at different stages of loading (Bornert et al 2012). The apparent mechanical transformation that links two digital images of the specimen surface under two different mechanical states can be done in a classical local approach or in a more recent global approach. In the classical local DIC, the displacements are computed by tracking the spatial correspondence between small sub-images from the Region Of Interest (ROI) in the reference configuration and in the deformed configuration. In the global DIC, the displacement field is computed over the whole ROI. In this paper, the DIC is processed using a local subset-based DIC software (Touchal et al 1996) and a global FE-based software (Hild and Roux 2008). 
A high-speed camera, a Photron SA5, is used to capture the images. This camera has a CMOS sensor with a maximum resolution of $1024 \times 1024$ pixels, a $20 \mu \mathrm{m}$ pixel size and a maximum shutter speed of $1 \mu \mathrm{s}$. The encoding depth of the images is 12 bits.

A key point in DIC is to evaluate the performance of the procedure. It can be done in an a priori phase using Correli Q4 routines (Hild and Roux 2008). In a first step, the texture of the white and black spray paint is analyzed to ensure a sufficient gray level amplitude and small scale details. In a second step a displacement uncertainty is evaluated by analyzing the displacement between the original image and a deformed image resulting from a prescribed displacement on the original image. The size of the correlation window will affect the performance of the results. The change in the standard displacement uncertainty $\sigma_{u}=\left\langle\left\|u_{e s t}-\left\langle u_{e s t}\right\rangle\right\|\right\rangle$ as a function of subset size $(l \times l)$ follows a power law decrease $\sigma_{u}=A^{\alpha+1} \times l^{-\alpha}$.

In this paper, the subset size of the Zones Of Interest (ZOI) is $20 \times 20$ pixels. A 20 pixels shift between two consecutive ZOI is chosen to map the whole ROI. This configuration allows sufficient accuracy, about $6 \times 10^{-3}$ pixels according to the a priori analysis, and more than 10 subsets in the specimen height. This uncertainty approach does not take into account the effect of noise during image acquisition. If no additional deformations are imposed between successive acquisitions, this noise can be reduced by image averaging. However this noise reduction cannot be applied when performing dynamic 
measurements. In order to get a better estimate of the uncertainty, a DIC is realized between a set of images recorded just before starting the test. This process will be detailed in subsection 3.3. Nevertheless we can already outline that the mean expected displacement uncertainty is about $3 \times 10^{-2}$ pixels in static experiments and $8 \times 10^{-2}$ pixels in dynamic experiments.

\section{Static flexural tests}

\subsection{Description of the test}

The three-point bending tests with a span of $L_{r o l}=120 \mathrm{~mm}$ are conducted on a MTS 20M electro-mechanical testing device.

The static experiments are performed following the international standard ISO 1920-3. All specimens were monotonically loaded at a displacement rate in the range $[0.1: 0.2] \mathrm{mm} / \mathrm{min}$ till failure. A $20 \mathrm{kN}$ load cell records the load during the experiment. Moreover, on all the samples a strain gauge is glued on the face opposed to the loading to register the maximal tensile strain of the beam.

\subsection{Flexural strength evaluation}

In accordance with ISO 1920-3, the static flexural strength is determined using the peak load. The ultimate flexural strength is directly given in terms of the maximal force $F$ as:

$$
f_{c f}=\frac{3}{2} \frac{F l}{h e^{2}}
$$


3.3 Digital Image Correlation

For the DIC, the region of interest corresponds to a rectangular shaped-area, $135 \times 40 \mathrm{~mm}$ in size, covering the support span and the whole height of the specimen. A close view of the ROI is shown in Fig. 2. Digital pictures were captured at 50 frames per second (fps) with a $1024 \times 1024$ pixels resolution.

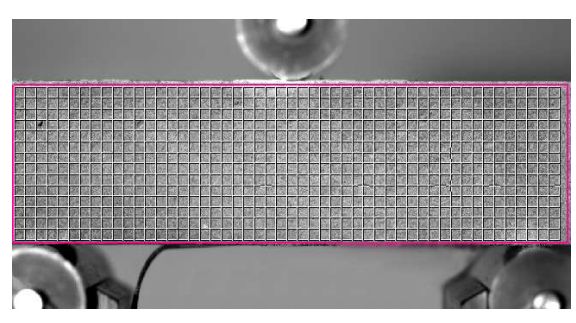

(a)

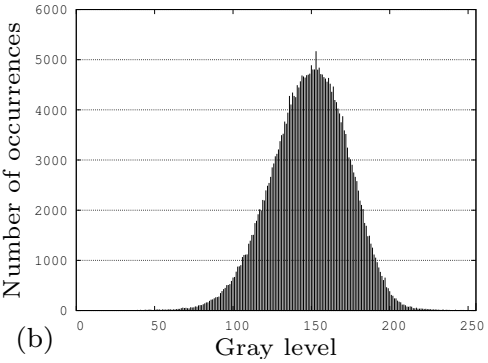

(b)
Gray level

Fig. 2: Close view of the ROI in static tests (a) and associated histogram of gray levels (b)

As previously explained in subsection 2.2 , in order to evaluate how noise in images propagates in displacement maps, a DIC is realized between a set of images at rest state. The experimentally obtained displacement fields distribution looks like a normal one, so we can assume that our expected uncertainty is equal to three times the standard deviation of the experimental distribution for a confidence level of $99.7 \%$. For the different static experiments, the expected displacement uncertainty is in the range $\left[1.3 \times 10^{-2}: 2.4 \times 10^{-2}\right]$ pixels with a mean value of about $1.9 \times 10^{-2}$ pixels or $2.5 \times 10^{-4} \mathrm{~mm}$. For a R30A7 concrete specimen tested in the proposed three-point bending test configuration and assuming a Young's modulus around $45 \mathrm{GPa}$ and a flexural 
strength around $7 \mathrm{MPa}$, the maximum vertical displacement at rupture will be around $15 \mu \mathrm{m}$. As a consequence, the expected uncertainty may represent between 10 to $25 \%$ of the maximum vertical displacement.

In static experiments, the DIC is not fundamentally needed to evaluate the flexural strength since the latter is directly deduced from the maximum load (eq. 1). Nevertheless, it can be used to determine material parameters. In addition, Young's modulus will be identified thanks to the finite element updating method (FEMU).

\subsection{FEMU}

The FEMU method (Kavanagh and Clough 1971) consists in performing iteratively finite element simulations so as to find the ideal set of material parameters that minimizes the difference between measured and computed fields. Due to its versatility, the FEMU method is extensively used in mechanical parameters identification based on full-field measurements (Avril et al 2008). Depending on the choice of the cost function, different FEMU formulations exist. In this paper, we used the classical output residual method which consists in minimizing the difference, in the least square sense, between the computed and measured displacements (cf. equation 2). This choice was motivated by the fact that this approach is known to be less sensitive to noise measurements 
than the input residual method.

$$
\mathfrak{F}(\theta)=\frac{1}{2} \sum_{j=1}^{n}\left\|\underline{U}_{m e s u}(j)-\underline{U}_{c a l c}(\theta, j)\right\|^{2}
$$

where $n$ is the amount of measurement points and $\theta$ the parameter set we are looking for.

This method requires a finite element analysis which is performed with Cast3M solver (Cast3M 2014) to compute the nodal displacements $U_{\text {calc }}(\theta)$. In the case of small perturbations and linear material behavior, the global equilibrium of the solid is written as:

$$
[K(\theta)]\{U\}=\{F\}
$$

where $[K(\theta)]$ is the stiffness matrix and $\{F\}$ the vector of generalized nodal forces. The constant stiffness matrix is built through the relationship:

$$
[K(\theta)]=\int_{\Omega}[B]^{T}[A(\theta)][B] d v
$$

where $[B]$ is the deformation matrix and $[A(\theta)]$ the material behavior matrix.

Different methods are appropriate to minimize the functional $\mathfrak{F}$. Among these, we chose the classical Gauss-Newton method. In order to avoid numerically induced errors, the gradients of the objective function are computed 
semi-analytically. The derivative of the stiffness matrix is evaluated by:

$$
\left[\frac{\partial K(\theta)}{\partial \theta}\right]=\int_{\Omega}[B]^{T}\left[\frac{\partial A(\theta)}{\partial \theta}\right][B] d v
$$

with the use of the analytical gradient of the material behavior matrix.

Before analyzing the experimental results, a preliminary evaluation of the parameter identification is performed with synthetic data. A finite element reference numerical solution is determined with realistic R30A7 concrete mechanical parameters: Young's modulus $E=43 G P a$ and Poisson's ratio $\nu=0.2$. The displacement data are blurred by noise:

$$
U_{\text {noise }}=U_{r e f}+\delta \eta U_{r e f}^{\max }
$$

where $-1 \leq \eta \leq 1$ is a random value, $\delta$ is the percentage of noise and $U_{r e f}^{\max }$ is the maximal displacement in the specimen.

The identification was performed with different mesh sizes of the ROI and different noise percentages. For each mesh size, one hundred different noised displacement datasets were used. The initial values are chosen as $E=10 G P a$ and $\nu=0.15$. The results of the identification are reported in Table 2 with the mean values for the identified Young's modulus and Poisson's ratio and the associated standard deviation. 
Table 2: Influence of mesh refinement on the parameter identification, Young's Modulus, E, in GPa

\begin{tabular}{ccccc}
\hline Noise & \multicolumn{3}{c}{ Mesh size: $N_{\text {Transverse }} \times N_{\text {Longitudinal }}$ elements } \\
intensity & $4 \times 16$ & $12 \times 48$ & $20 \times 80$ & $40 \times 160$ \\
\hline \multirow{2}{*}{$5 \%$} & $E=42.47 \pm 1.32$ & $E=43.02 \pm 0.45$ & $E=42.96 \pm 0.34$ & $E=42.98 \pm 0.16$ \\
& $\nu=0.21 \pm 0.08$ & $\nu=0.19 \pm 0.03$ & $\nu=0.2 \pm 0.02$ & $\nu=0.2 \pm 0.01$ \\
$10 \%$ & $E=41.20 \pm 3.2$ & $E=42.97 \pm 0.88$ & $E=42.88 \pm 0.69$ & $E=42.95 \pm 0.32$ \\
& $\nu=0.24 \pm 0.13$ & $\nu=0.19 \pm 0.08$ & $\nu=0.20 \pm 0.04$ & $\nu=0.20 \pm 0.02$ \\
$20 \%$ & $E=42.33 \pm 3.25$ & $E=42.74 \pm 2.39$ & $E=42.62 \pm 1.38$ & $E=42.87 \pm 0.66$ \\
& $\nu=0.22 \pm 0.23$ & $\nu=0.17 \pm 0.14$ & $\nu=0.21 \pm 0.09$ & $\nu=0.20 \pm 0.04$ \\
\hline
\end{tabular}

It can be seen that an important level of noise induces an important bias on the parameter identification and that uncertainty decreases with mesh size. Assuming that a discrepancy lower than 5\% remains an acceptable result, it appears that, except for the smallest mesh size, Young's modulus identification is satisfactory, even with a noise up to $20 \%$ and that, conversely, Poisson's ratio cannot be identified with a sufficient level of accuracy, except for the finest mesh and the smallest noise. This result was expected since, even if the specimen is a short beam, the flexural response is less sensitive to Poisson's ratio than to Young's modulus. An example of the initial displacement fields with $10 \%$ of noise and the FEM simulated one is shown in Figures 3(a) and 3(b) with a $200 \times$ amplified deformed shape.

\subsection{Static results}

Nine dry specimens of R30A7 were subjected to static flexural tests. Results are reported in Table 3 . The strain rate was evaluated thanks to the strain gauge glued in the central region on the most tense fiber. A first value of 


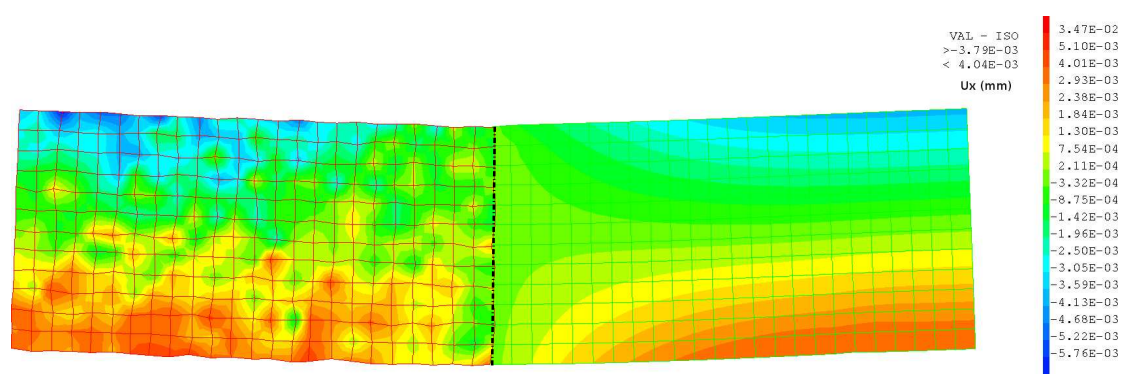

(a) longitudinal displacement field

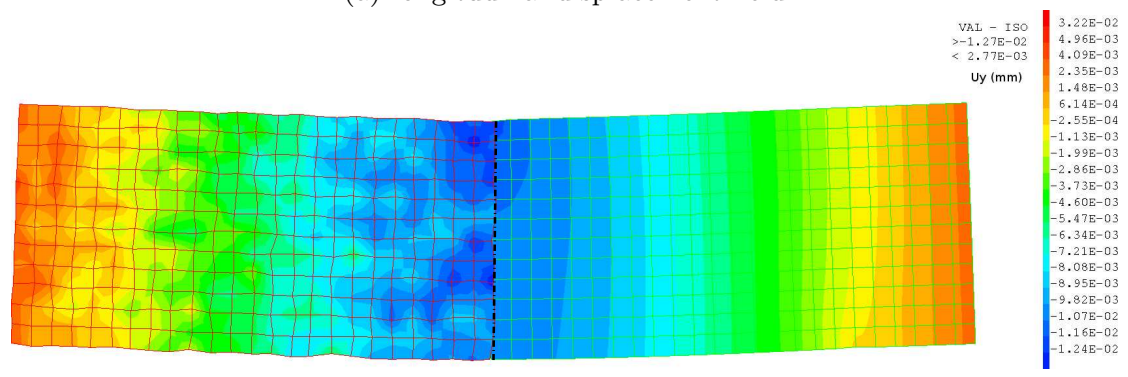

(b) transversal displacement field

Fig. 3: Comparison of displacement fields from synthetic noisy date (left) and FEMU identification (right)

Young's modulus is obtained from the strain gauge measurement and another is deduced from frequency resonance measurements. This latter value shows a very low standard deviation due to the rigorous manufacturing procedure. The identified values are consistent with data reported in literature concerning R30A7 concrete (Erzar and Forquin 2011).

The FEMU procedure is applied to the experimental displacement field deduced from DIC on sample S7. In accordance with the preliminary evaluation of the parameter identification with synthetic data, only Young's modulus is identified. A comparison is made with Young's modulus value determined with the frequency study $E=43.46 G P a$. The parameter identification is performed at different loading levels. The computed Young's modulus are listed 
Table 3: Static experimental results

\begin{tabular}{|c|c|c|c|c|c|c|}
\hline $\begin{array}{c}\text { Test } \\
\text { number }\end{array}$ & $\begin{array}{l}\text { Maximum } \\
\text { force } \\
F[N]\end{array}$ & $\begin{array}{c}\text { Loading } \\
\text { speed } \\
V[\mathrm{~mm} / \mathrm{min}]\end{array}$ & $\begin{array}{l}\text { Strain } \\
\text { rate } \\
\dot{\varepsilon}\left[s^{-1}\right]\end{array}$ & $\begin{array}{l}\text { Flexural } \\
\text { strength } \\
\quad f_{c f}\end{array}$ & $\begin{array}{c}\text { Young's modulus } \\
\text { gauge identification } \\
E_{g}[G P a]\end{array}$ & $\begin{array}{c}\text { Young's modulus } \\
\text { frequency resonance } \\
E_{f}[G P a]\end{array}$ \\
\hline S1 & 2666 & 0.2 & $5.77 \times 10^{-6}$ & 7.50 & 46.87 & \\
\hline $\mathrm{S} 2$ & 2506 & 0.2 & $3.79 \times 10^{-7}$ & 7.05 & 40.17 & \\
\hline S3 & 2606 & 0.2 & $2.29 \times 10^{-6}$ & 7.33 & 46.82 & \\
\hline S4 & 2620 & 0.2 & $3.13 \times 10^{-6}$ & 7.37 & 46.61 & \\
\hline S5 & 2804 & 0.1 & $2.56 \times 10^{-6}$ & 7.88 & 44.61 & 43.25 \\
\hline S6 & 1966 & 0.1 & $3.79 \times 10^{-6}$ & 5.53 & 42.02 & 43.06 \\
\hline S7 & 3195 & 0.2 & $5.59 \times 10^{-6}$ & 8.99 & 45.10 & 43.46 \\
\hline S8 & 3051 & 0.2 & $5.30 \times 10^{-6}$ & 8.58 & 44.87 & 42.88 \\
\hline S9 & 2735 & 0.2 & $4.15 \times 10^{-6}$ & 7.69 & 39.87 & 43.58 \\
\hline Mean & 2683 & & $3.66 \times 10^{-6}$ & 7.55 & 44.10 & 43.25 \\
\hline
\end{tabular}

in Table 4. A very good agreement is found between values deduced from the coupled FEMU-DIC procedure and the resonance frequency approach.

Table 4: Coupled FEMU-DIC Young's modulus identification

\begin{tabular}{c|ccc} 
Load $(\mathrm{N})$ & 1000 & 1500 & 2000 \\
\hline E [GPa] & 44.05 & 41.92 & 42.92 \\
\hline Relative gap & $1.36 \%$ & $-3.54 \%$ & $-1.24 \%$
\end{tabular}

\section{Dynamic flexural tests}

\subsection{Description of the tests}

A Split Hopkinson Pressure Bar (SHPB) system is used to carry on dynamic tests. In order to perform tests similar to the static case, we chose a three-point bending configuration. The experimental set-up for the dynamic flexural test is shown in Figure 4. 


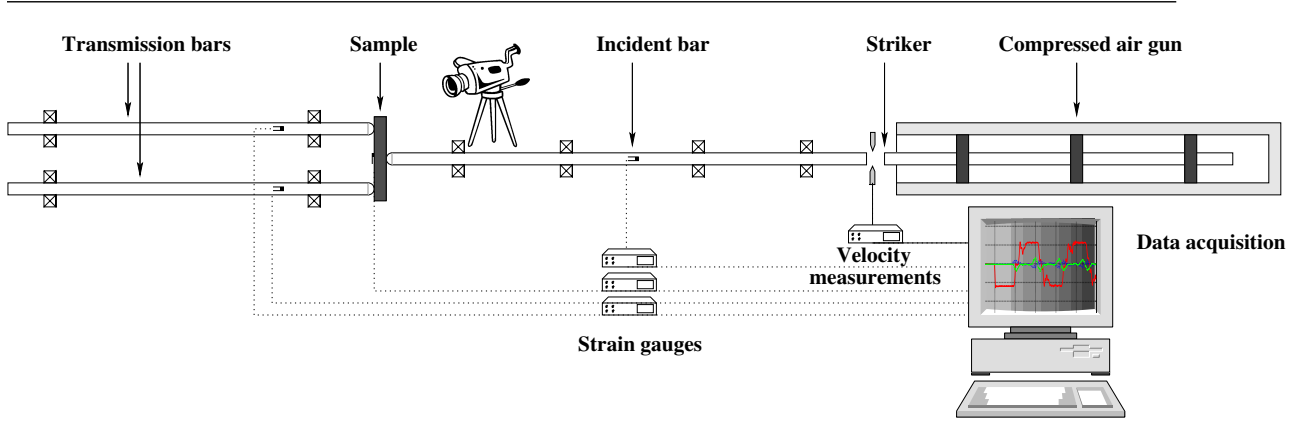

Fig. 4: SHPB device in three-point bending configuration

As in static experiments, on all the samples, we glued a strain gauge on the face opposed to the loading to register the maximal tensile strain of the beam.

When testing concrete, aluminum bars are usually used for the SHPB device (Schuler et al 2006), (Delvare et al 2010), (Erzar and Forquin 2010),(Hanus et al 2012). However in this work we chose to use nylon bars. This configuration presents two main advantages. On the one hand, we can have a better assessment of the reflected and transmitted waves. This is due to the lower ratio of the material mechanical impedances $(Z=\sqrt{E \rho})$ between nylon and concrete (Tab. 5). On the other hand, it is possible to study the concrete's response at lower strain rates. In fact the use of aluminum or steel bars limits the study to strain rates over $9.5 \mathrm{~s}^{-1}$ (Hanus et al 2012).

One of the biggest advantages of using the SHPB device is that both the force and velocity measurements are known at the interface between the sample and the incident bar. These measures are obtained from incident and reflected waves by the classic equations (7) and (8). 
Table 5: Mechanical properties of pressure bars and concrete

\begin{tabular}{c|ccccc} 
& $E[\mathrm{GPa}]$ & $\rho\left[\mathrm{kg} / \mathrm{m}^{3}\right]$ & $\nu$ & $C[\mathrm{~m} / \mathrm{s}]$ & $Z\left[\mathrm{Ns} / \mathrm{m}^{3}\right]$ \\
\hline Nylon & 3.3 & 1150 & 0.39 & 1693 & $1.95 \times 10^{6}$ \\
Aluminum & 69 & 2700 & 0.33 & 5055 & $1.36 \times 10^{7}$ \\
Concrete & 42 & 2300 & 0.20 & 4273 & $9.83 \times 10^{6}$
\end{tabular}

$$
F_{i}=E_{B} S_{B}\left(\varepsilon_{i}+\varepsilon_{r}\right)
$$

where $E_{B}$ is Young's modulus of the bar and $S_{B}$ the cross sectional area of the bars.

$$
V_{i}=C_{B}\left(\varepsilon_{i}-\varepsilon_{r}\right)
$$

where $C_{B}=\sqrt{E_{B} / C_{B}}$ is the uniaxial wave speed in the bars.

However, when using the SHPB device, particular attention must be paid to the transport of waves measured in the middle of the incident bar to the specimen/bars interface. Since the nylon pressure bars have a viscoelastic behavior, precise time shifting and dispersion corrections are performed with the software David (Zhao and Gary 1996), (David 2015). Typical corrected input $\left(F_{i}\right)$ and output forces $\left(F_{s}^{1}\right.$ and $\left.F_{s}^{2}\right)$ are reported in Figure 5 which obviously shows that equilibrium is not achieved during the test. 


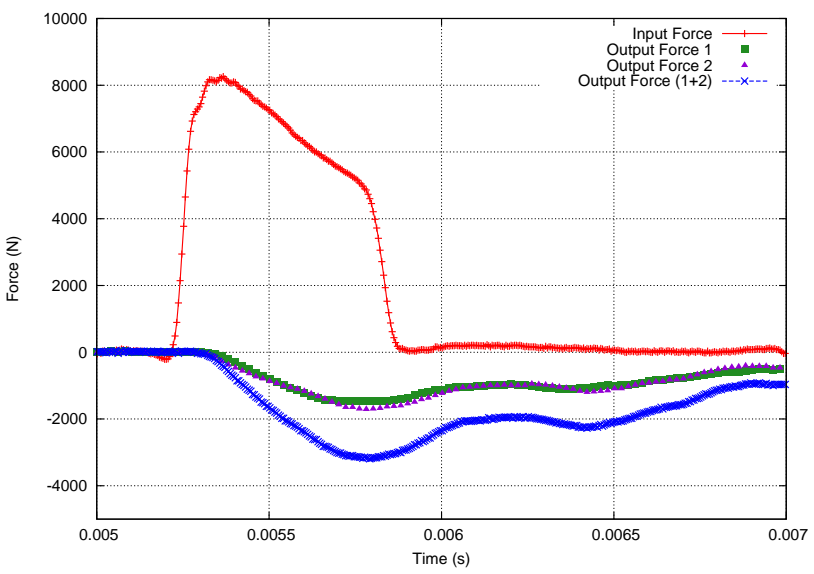

Fig. 5: Typical corrected input and output forces

4.2 Flexural strength evaluation

In dynamic experiments, inertial effects play a very important role. The consequences are that fracture may not occur at the maximum input force and that at high speed, the support's reaction may appear after specimen fracture, so that the test is equivalent to a one-point bending test. These observations were used to propose an infinite beam model to evaluate the flexural strength of brittle materials (Delvare et al 2010), (Hanus et al 2012). However, at lower strain rates, the reaction forces may influence the loading history of the specimen. Accordingly, it was decided to use a numerical model created with the finite element code Cast3M. Displacement-controlled and force-controlled finite element simulations are performed. Implicit simulations based on Newmark algorithm and explicit simulations using the central difference algorithm were performed under the plain strain assumption. Assuming an elastic re- 
sponse until fracture, the onset of failure is determined by the loss of equality between:

- the displacements, computed in the force-controlled simulation and measured;

- the strains in the most tense fiber, computed in the force and displacementcontrolled simulations.

Since a strain gauge was glued on the face opposed to loading, the procedure can also be assessed by comparing the computed strains and the measured ones. The strain gauge measurements are also used to determine the strain rate during the tests.

A preliminary analysis is done with an experiment, referred to as Test A, during which the specimen behaves elastically due to an insufficient striker velocity. As expected, there is neither difference in displacement nor in strains in Figure 6 between force and displacement-controlled simulations. Furthermore, Figure 6 shows a very good agreement between strains measured by the gauge and strains deduced from an elastic dynamic finite element computation when the specimen behaves elastically during the whole useful part of the test. 

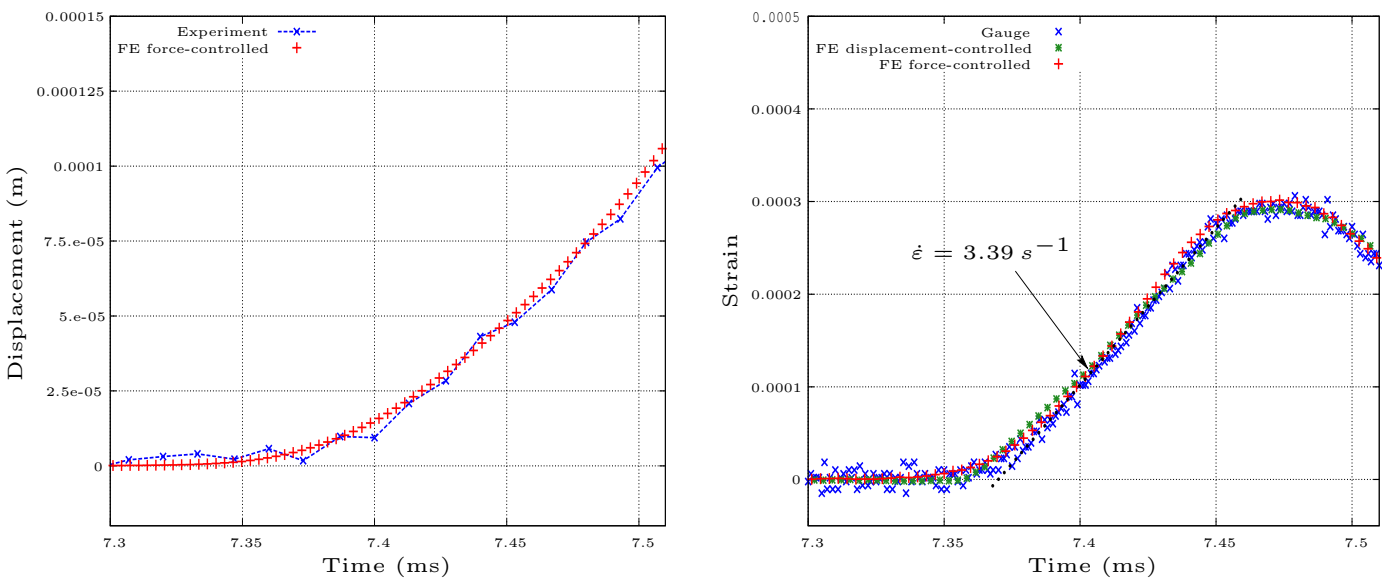

Fig. 6: Test A - elastic response

Comparison between measured and computed displacements (left) and comparison between measured and computed strains in force and displacement-controlled simulations (right)

In the following, the procedure is then applied to two other representative experiments, referred to as Test B and Test C, during which failure occurs. The fracture time is determined by a sudden change of slope $\left(\frac{d \varepsilon}{d t}\right)$ in the gauge response. Two cases are encountered: an increase, when fracture takes place on the gauge, and a decrease, when fracture takes place outside the gauge. The second situation, observed in Test B, occurs less frequently. 

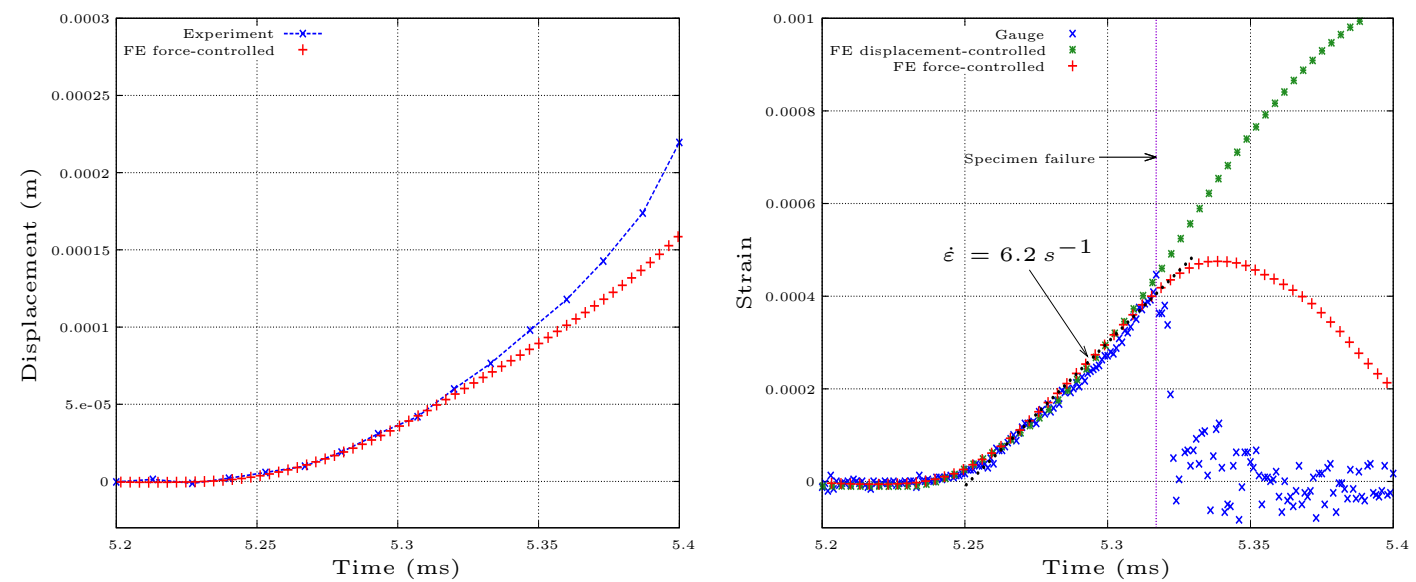

Fig. 7: Test B - elastic response

Comparison between measured and computed displacements (left) and comparison between measured and computed strains in force and displacement-controlled simulations (right)

The results, shown in Figure 7 and 8, indicate a same time to failure $t_{f}=5.32 \mathrm{~ms}$ comparing displacements or strains of Test B and a same time to failure $t_{f}=5.06 \mathrm{~ms}$ comparing displacements or strains of Test C. Considering Test $\mathrm{C}$, as shown in Figure 8, only the strains comparison allows to identify clearly the time to failure $t_{f}=5.06 \mathrm{~ms}$. The very good match between measured and computed strains is also observed until fracture of the specimen in Test B (Figure 7) and Test C (Figure 8). Furthermore the onset of failure is detected simultaneously by the sudden slope change in gauge response or the loss of equivalence between force-controlled and displacement-controlled numerical simulations. 

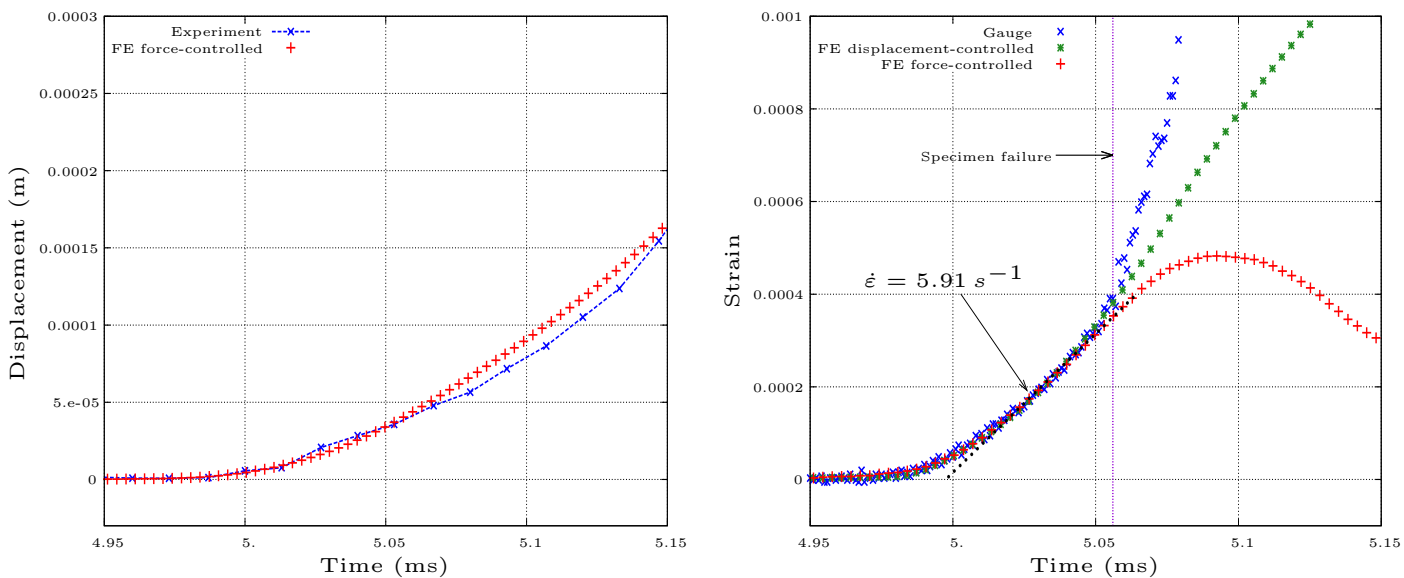

Fig. 8: Test $\mathrm{C}$ - elastic response

Comparison between measured and computed displacements (left) and comparison between measured and computed strains in force and displacement-controlled simulations (right)

At this stage, it is worth noticing that the maximum vertical displacement reached at failure remains very small, typically in the order of $5 \times 10^{-5} \mathrm{~m}$. This comment equally applies to the strain values with a maximum value lower than $4 \times 10^{-4}$.

\subsection{Digital Image Correlation}

A compromise between frame rate and image resolution is adopted so that digital pictures were captured at 75000 fps with a reduced $320 \times 264$ pixels resolution. In order to get a sufficient number of subsets in the transverse direction, the region of interest corresponds to a rectangular shaped-area, $62 \times$ $40 \mathrm{~mm}$ in size, covering half of the support span and the whole height of the specimen. A close view of the ROI and the associated histogram of gray levels 
are shown in Fig. 9.
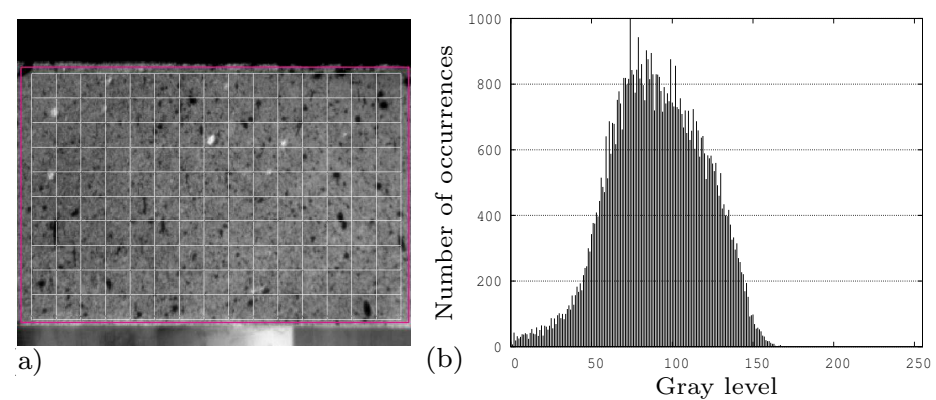

Fig. 9: Close view of the ROI in dynamic tests (a) and histogram of gray levels (b)

Figure 10 shows the qualitative evolution of the longitudinal displacement field in the specimen during the bending test for the three proposed reference experiments. The displacement field is computed with a subset size of 20 pixels and a step size of 20 pixels. In sub-figures, the longitudinal displacement field is shown at three different times:

(a) before the maximum of the strain gauge response;

(b) and (c) near and a little after the maximum of the gauge response (Test A) or just after the onset of rupture (Tests B and C).

On these fields we can clearly see the difference in behavior of the specimen before (Fig. 10 (a)) and after the crack formation (Fig. 10 (b) and (c)) for reference Tests B and C. Before the onset of fracture, the horizontal displacement field associated with a bending state in the ROI is antisymmetric. In the case of Test A, this antisymmetric state remains during the whole useful part of the test. 
(a)

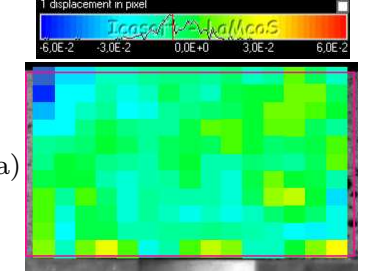

$\mathrm{t}=7.400 \mathrm{~ms}$

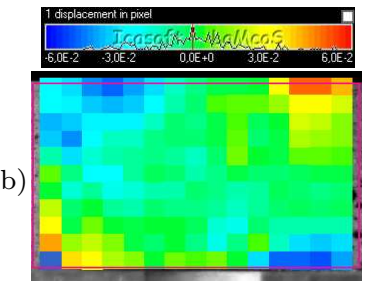

$\mathrm{t}=7.467 \mathrm{~ms}$

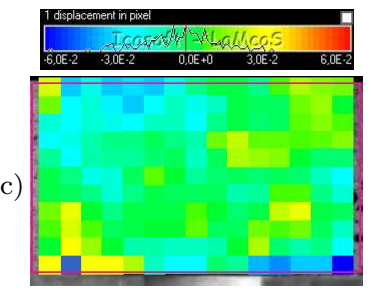

$\mathrm{t}=7.533 \mathrm{~ms}$
Test B

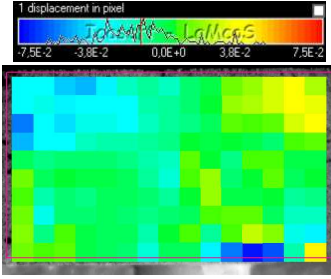

$\mathrm{t}=5.307 \mathrm{~ms}$

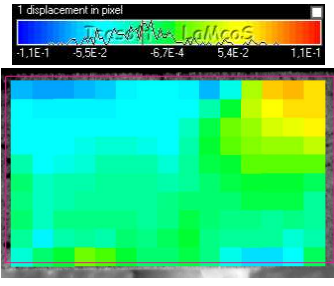

$\mathrm{t}=5.347 \mathrm{~ms}$

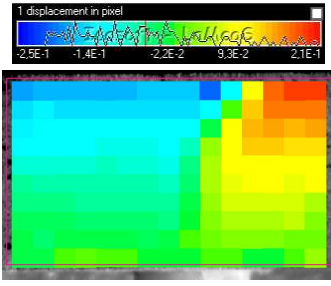

$\mathrm{t}=5.404 \mathrm{~ms}$
Test C

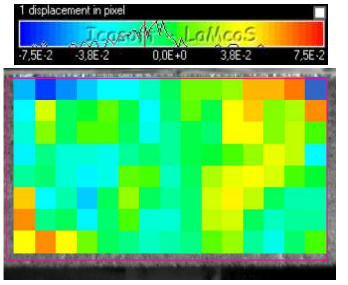

$\mathrm{t}=5.040 \mathrm{~ms}$

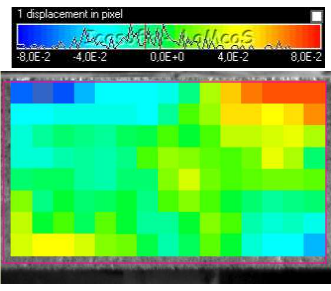

$\mathrm{t}=5.080 \mathrm{~ms}$

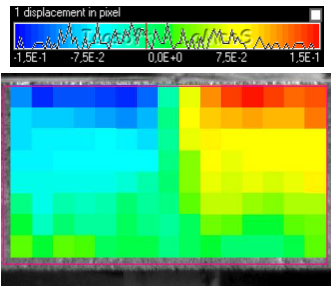

$\mathrm{t}=5.133 \mathrm{~ms}$

Fig. 10: Longitudinal displacement fields - subset and grid size set to 20 pixels $^{2}$

The numerical simulation of Test A is used in order to confirm this observation with un-noisy displacement fields. Results are shown in Figure 11. This simulation reveals that very early in the loading of the specimen - the effective part of the test begins at $7.35 \mathrm{~ms}$ (see Fig. 6) - an antisymmetric longitudinal displacement field appears in the central part of the specimen.

During a test with failure of the specimen, the crack propagation initiates on the face opposed to the loading. In a bidimensional representation of the 
specimen, the most tense fiber is the first one to be damaged and as a result, the neutral axis will move and the longitudinal displacement field will not be antisymmetric anymore. To take advantage of this situation, we propose to define a crack indicator which considers the term to term sum of horizontal displacements from superior and inferior fibers. This indicator is described by the equation $(9)$ :

$$
\Lambda(t)=\frac{1}{n_{c}} \sum_{i=1}^{n_{c}}\left|U_{x}^{(i, 1)}(t)+U_{x}^{\left(i, n_{r}\right)}(t)\right|
$$

where $n_{c}$ and $n_{r}$ are respectively the number of subsets in horizontal and vertical directions and $U_{x}$ is the longitudinal displacement.

When the specimen behaves elastically, the indicator value must remain constant and equal to zero in the absence of longitudinal rigid body motion. On the contrary, a sudden increase of the indicator value can be interpreted as the appearance of a macroscopic crack.

The proposed approach has been applied to the three reference tests. As expected during Test A, where the specimen behaves elastically, the indicator value remains equal to zero (Figure 12). For the two other tests showing a fracture, a quick growth in the indicator value is observed at the precise moment when the gauge signal drops to zero (Test B, Figure 13) or abruptly increases (Test C, Figure 14). 


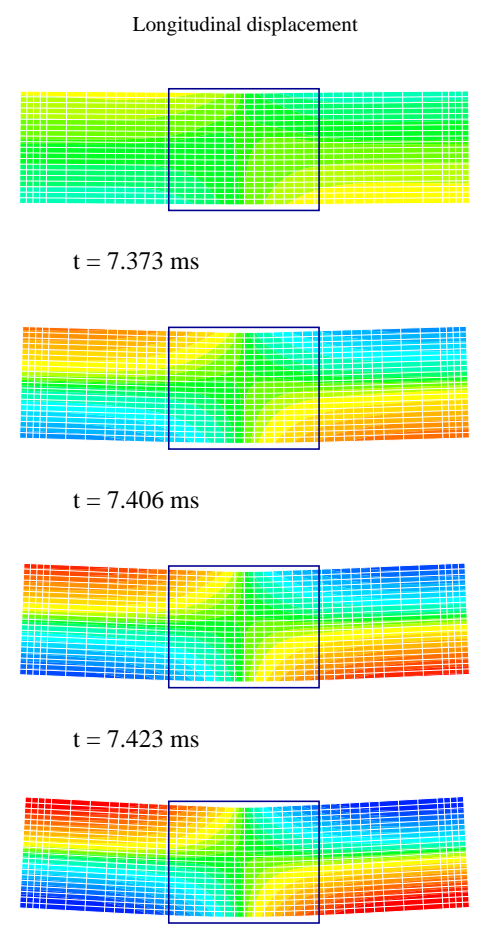

Transversal displacement

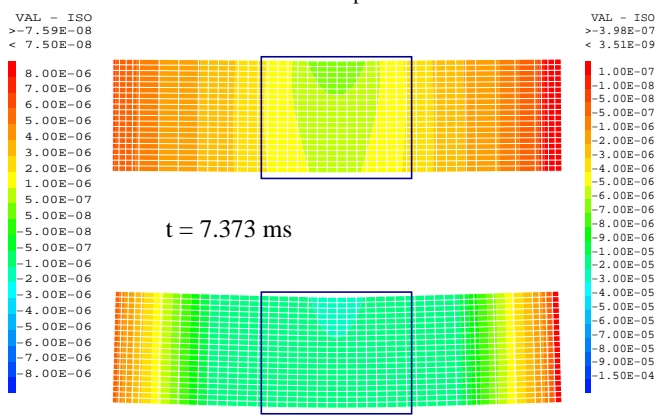

$\mathrm{t}=7.406 \mathrm{~ms}$

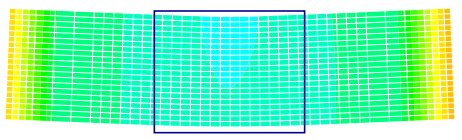

$\mathrm{t}=7.423 \mathrm{~ms}$

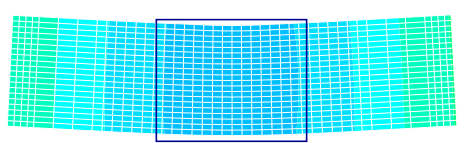

$\mathrm{t}=7.456 \mathrm{~ms}$

$\mathrm{t}=7.456 \mathrm{~ms}$

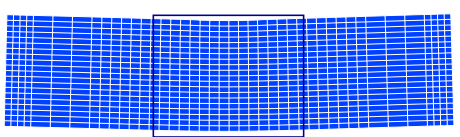

$\mathrm{t}=7.522 \mathrm{~ms}$

Fig. 11: Simulated displacement fields associated with Test A with the ROI for DIC superimposed

On the three figures, we also add the strain in the most tensile fiber computed from DIC. It clearly appears that the influence of noise on the measurements is higher for DIC strain than for DIC crack indicator and that these DIC strains are not exploitable directly without significant filtering. 


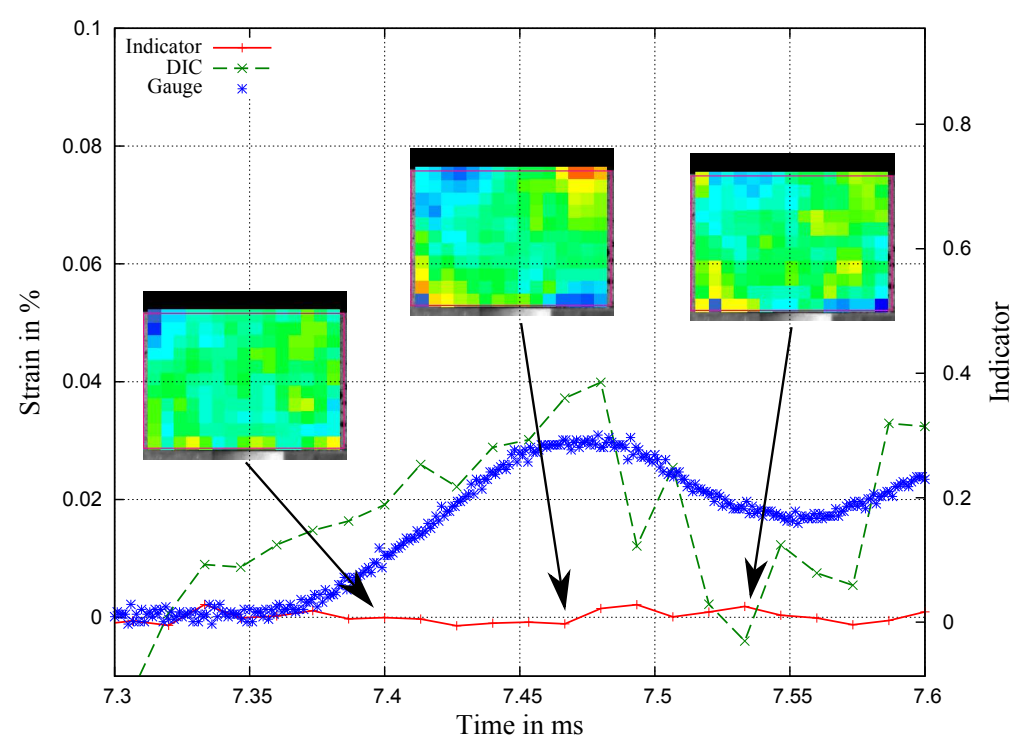

Fig. 12: Crack indicator history: Test A

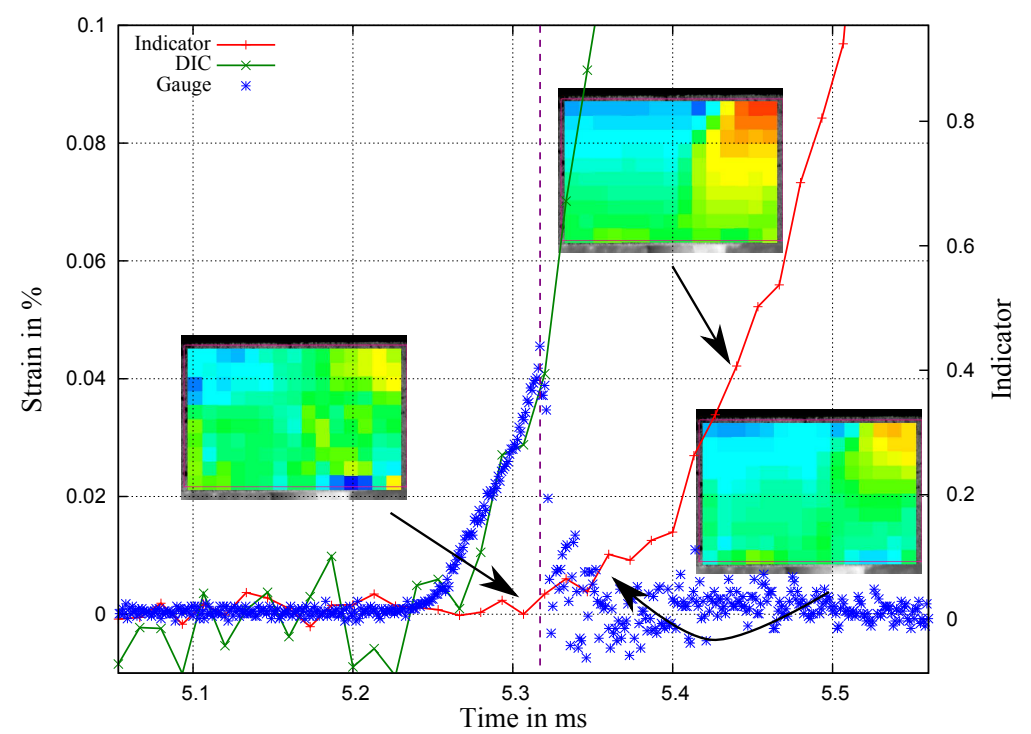

Fig. 13: Crack indicator history: Test B

\subsection{Dynamic results}

The results of the dynamic tests are listed in Table (6). The impactor velocity and the strain rates obtained from the gauge measurements, as well as 


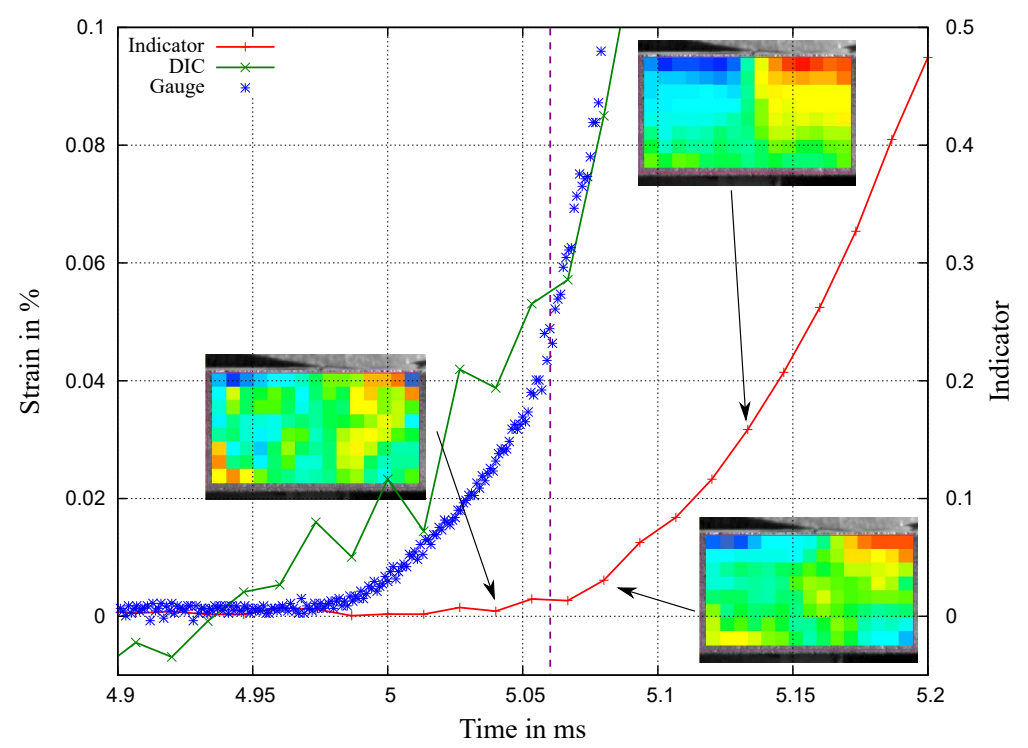

Fig. 14: Crack indicator history: Test C

the stress attained, are also presented. For this experimental set up, the strain rates reached are between 1 and $15 \mathrm{~s}^{-1}$. The time to failure has been evaluated with the proposed crack indicator term and has always been found consistent with the one deduced from the gauge measurements. The dynamic ultimate flexural strength is deduced from FE computations when the sample cracks. It must be emphasized that the first eight tests listed in Table (6) did not lead to the rupture of the specimen. As a consequence, the dynamic ultimate flexural strength is not evaluated but is necessarily greater than the reported value. 
Table 6: Overview of the results of the dynamic tests on concrete

\begin{tabular}{l|ccc} 
& $V_{\text {impact }}[\mathrm{m} / \mathrm{s}]$ & $\dot{\varepsilon}\left[\mathrm{s}^{-1}\right]$ & $f_{c f}[\mathrm{MPa}]$ \\
\hline 1 & 07.15 & 1.45 & $>5.67$ \\
2 & $/$ & 1.50 & $>6.13$ \\
3 & $/$ & 1.80 & $>5.67$ \\
4 & 08.32 & 1.87 & $>6.68$ \\
5 & 07.45 & 2.00 & $>6.23$ \\
6 & 10.45 & 2.14 & $>7.98$ \\
7 & 12.33 & 3.03 & $>9.87$ \\
8 & 16.54 & 3.39 & $>12.60$ \\
\hline 9 & 18.24 & 3.97 & 13.38 \\
10 & $/$ & 5.98 & 16.37 \\
11 & 27.26 & 5.89 & 15.30 \\
12 & 26.34 & 6.80 & 17.90 \\
13 & $/$ & 6.20 & 17.13 \\
14 & $/$ & 12.31 & 20.80
\end{tabular}

\section{Dynamic Increase Factor}

We can make use of the results obtained to follow the evolution of the Dynamic Increase Factor (DIF) with the strain rate. The DIF is defined as:

$$
D I F=\frac{f_{c t}^{d y n}}{f_{c t}^{s t a t}}
$$

The DIF is meaningful in this work because the static and dynamic tests were performed in a very similar way. The sample has the same dimensions and the span length is identical. At this stage, it must be emphasized that in this study, in coherence with the normalized static ultimate flexural strength definition, the concrete is considered as a pure brittle material. According to this approach the DIF of concrete is between 1.8 and 2.6 for a strain rate within 4 and $15 \mathrm{~s}^{-1}$. Our new results, consistent with other experimental results, are added to Figure 1 and presented in Figure 15. 


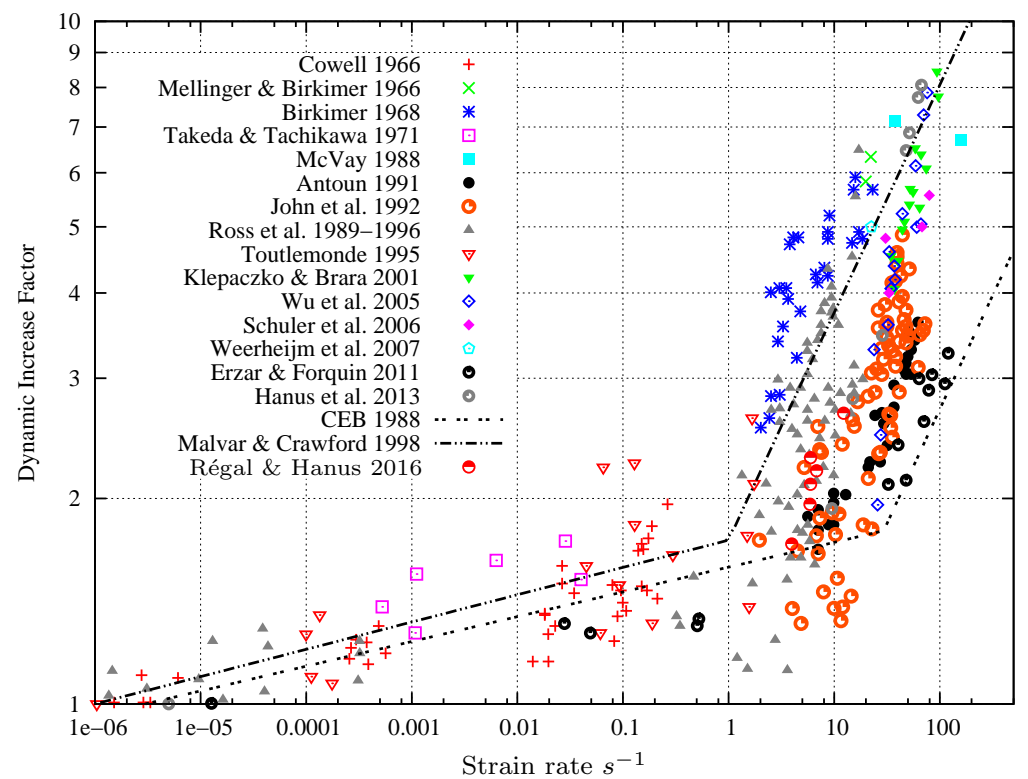

Fig. 15: Updated strain rate influence on tensile strength

\section{Failure mechanisms}

The failure modes of the specimen under quasi-static loading and dynamic loadings are shown in Figure 16.

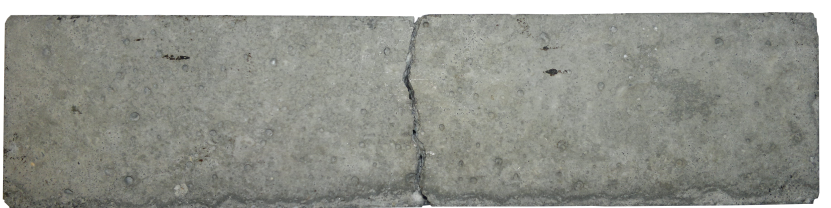

(a)

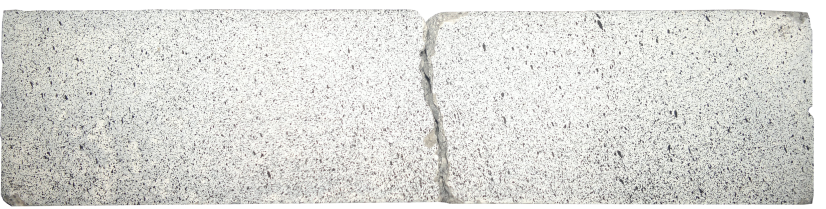

(b)

Fig. 16: Typical failure modes: (a) quasi-static loading; (b) dynamic loading

The same main crack orientations are observed: transversal, parallel to the loading direction that specifically characterizes a bending failure mode. Con- 
trary to what has been previously observed (Bailly P. et al 2009), there is no transition from bending failure to shear failure in dynamic experiments. This can be explained by an insufficient loading rate which remains moderate in our SHPB experiments.

The fracture surface of specimens was examined at macro-scale using a high-resolution digital camera equipped with double-telecentric lenses.

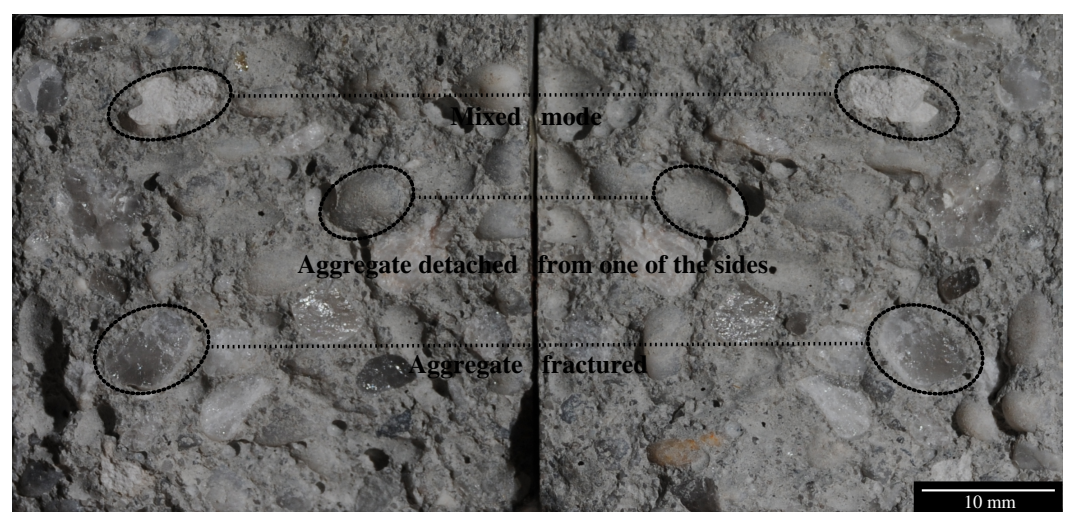

(a)

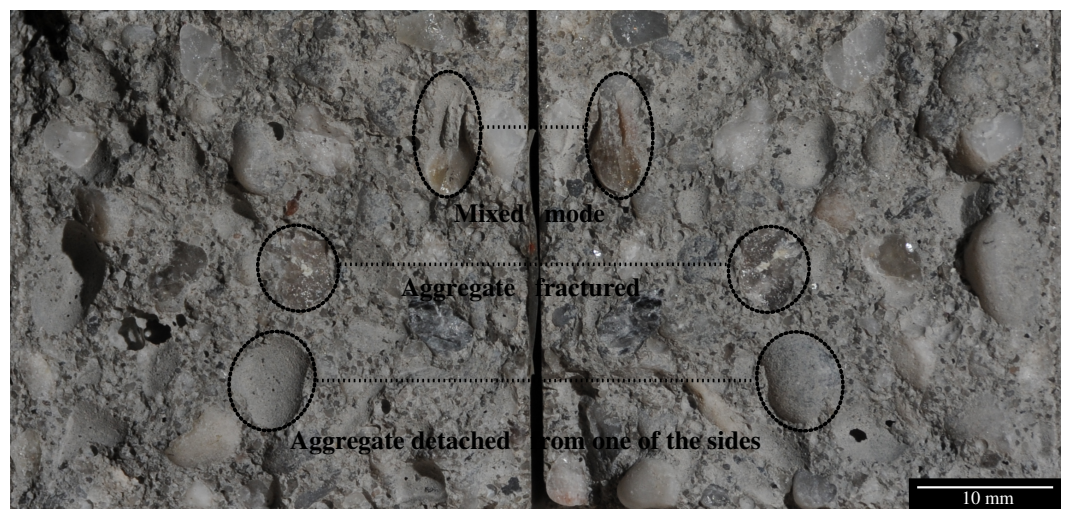

(b)

Fig. 17: Typical fracture surfaces: (a) quasi-static loading; (b) dynamic loading 
Depending on the properties of the raw materials as well as on the manufacturing process, two different dominant fracture types are usually found for plain concrete specimens: intergranular for concrete with weak interfaces, and transgranular for concrete with strong interfaces. The observation of Figure 17 (a) reveals the presence of both fractured and circumvented aggregates in quasi-static experiment which can be explained by the very high-quality cement used.

It is usually observed that there is an increasing number of broken aggregates with an increasing strain rate and that the fracture surfaces become more and more flattened (Brara and Klepaczko 2007), (Chen X. et al 2014). This trend is not observed in the SHPB tests. Comparing Figure 17(a) and Figure 17(b), it can be concluded that there is no significant difference between static and dynamic failure mechanisms. A similar observation was done by (Vegt I. et al 2007) who have found that more broken aggregate particles were only observed at very high loading rates. Within the range of strain rates studied, as in quasi-static experiments, the cracks have sufficient time to find the weakest path, either they circumvent aggregate particles or they propagate through them.

\section{Conclusions}

This paper proposed an experimental investigation of the tensile behavior of concrete under high strain rates in the range from $1 / \mathrm{s}$ to $15 / \mathrm{s}$. It focused on the study of the flexural strength and the evaluation of dynamic increase factors. 
The method's originality lies in the use of the same specimen geometry and loading configuration in both static and dynamic experiments. The evaluation of the flexural strengths in both static and dynamic experiments is consistent so that evaluating a dynamic increase factor is meaningful. In the study, the DIC technique was used in conjunction with very high-speed photography. Even if fracture occurs at very low displacements and strains, the DIC has been found suitable for Young's modulus identification with a FEMU approach in static experiments. Despite a moderate image resolution to ensure a sufficient frame rate, the DIC has also been found suitable for crack detection during dynamic tests. The time to fracture computed from the DIC is consistent with those computed from load and displacement-controlled FE simulations, as well as with strain gauge measurements.

Acknowledgements The authors would like to thank French Region Centre Val de Loire (in the framework of IMFRA2 APR-2012) for supporting this project.

\section{References}

Avril S, Bonnet M, Bretelle AS, Grédiac M, Hild F, Ienny P, Latourte F, Lemosse D, Pagano S, Pagnacco E, Pierron F (2008) Overview of identification methods of mechanical parameters based on full-field measurements. Experimental Mechanics 48(4):381-402

Belenky A, Rittel D (2011) A Simple Methodology to Measure the Dynamic Flexural Strength of Brittle Materials. Experimental Mechanics 51(8):1325-1334

Bischoff PH, Perry SH (1991) Compressive behaviour of concrete at high strain rates. Materials and Structures 24:425-450 
Bornert M, Hild F, Orteu JJ, Roux S (2012) Digital Image Correlation. In: Full-Field Measurements and Identification in Solid Mechanics, John Wiley \& Sons, Inc., pp 157-190

Brara A, Klepaczko JR (2007) Fracture energy of concrete at high loading rates in tension. International Journal of Impact Engineering 34(3):424-435

Cast3M (2014) Finite element solver Cast3M. http://www-cast3m.cea.fr/, [Online; accessed may-2016]

CEB (1988) Concrete structures under impact and impulsive loading: synthesis report. Bulletin d'information, Comité euro-international du béton

Daimaruya M, Kobayashi H (2000) Measurements of impact tensile strength of concrete and mortar using reflected tensile stress waves. J Phys IV France 10(PR9):173-178

David (2015) SHPB tests analysis software David. https://www.sites.google.com/site/ hopkinsonbars/home/david, [Online; accessed may-2016]

Delvare F, Hanus JL, Bailly P (2010) A non-equilibrium approach to processing hopkinson bar bending test data: Application to quasi-brittle materials. International Journal of Impact Engineering 37(12):1170-1179

DoD (2008) UFC 3-340-02, structures to resist the effects of accidental explosions. Tech. rep., Department of Defense, Washington DC, USA

Erzar B, Forquin P (2010) An experimental method to determine the tensile strength of concrete at high rates of strain. Experimental Mechanics 50(7):941-955

Erzar B, Forquin P (2011) Experiments and mesoscopic modelling of dynamic testing of concrete. Mechanics of Materials 43(9):505-527

Forquin P (2012) An optical correlation technique for characterizing the crack velocity in concrete. The European Physical Journal Special Topics 206:89-95

Gabet T, Malécot Y, Daudeville L (2008) Triaxial behaviour of concrete under high stresses: Influence of the loading path on compaction and limit states. Cement and Concrete Research 38(3):403-412

Hanus JL, Magnain B, Durand B, Alanis-Rodriguez J, Bailly P (2012) Processing dynamic split hopkinson three-point bending test with normalized specimen of quasi-brittle material. Mechanics \& Industry 13:381-393 
Hild F, Roux S (2008) Correli q4 a software for "finite-element" displacement field measurements by digital image correlation. Tech. rep., LMT Cachan

Kavanagh KT, Clough RW (1971) Finite element applications in the characterization of elastic solids. Int J Solids Strucrures 7:11-23

Klepaczko JR, Brara A (2001) An experimental method for dynamic tensile testing of concrete by spalling. International Journal of Impact Engineering 25(4):387-409

Malvar LJ, Crawford JE (1998) Dynamic increase factors for concrete. Tech. rep., DTIC Document

Pierron F, Forquin P (2012) Ultra-high-speed full-field deformation measurements on concrete spalling specimens and stiffness identification with the virtual fields method. Strain 48(5):388-405

Pierron F, Sutton MA, Tiwari V (2011) Ultra high speed dic and virtual fields method analysis of a three point bending impact test on an aluminium bar. Experimental Mechanics $51(4): 537-563$

Bailly P, Delvare F, Hanus J-L (2009) Experimental study of the behaviour of building structural elements under soft impact. In: 9th International Conference on the Mechanical and Physical Behaviour of Materials under Dynamic Loading (DYMAT), vol 1, pp $471-477$

Chen X, Wu S, Zhou J (2014) Experimental Study on Dynamic Tensile Strength of Cement Mortar Using Split Hopkinson Pressure Bar Technique. Journal of Materials in Civil Engineering 26(6)

Huang S, Luo S, Xia K (2009) Dynamic fracture initiation toughness andpropagation toughness of PMMA. In: Proceedings of the SEM Annual Conference, pp 1-4

Jiang F, Vecchio K (2009) Hopkinson Bar Loaded Fracture Experimental Technique: A Critical Review of Dynamic Fracture Toughness Tests. ASME Applied Mechanics Reviews $62(6)$

Pittari III J, Subhash G, Zheng J, Halls V, Jannotti P (2015) The rate-dependent fracture toughness of silicon carbide- and boron carbide-based ceramics . Journal of the European Ceramic Society 35(16):4411 - 4422 
Vegt I, van Breugel K, Weerheijm J (2007) Failure mechanisms of concrete under impact loading. In: 6th International Conference on Fracture Mechanics of Concrete and Concrete Structures, pp 579-587

Rossi P, Toutlemonde F (1996) Effect of loading rate on the tensile behaviour of concrete: description of the physical mechanisms. Materials and Structures 29(2):116-118

Schuler H, Mayrhofer C, Thoma K (2006) Spall experiments for the measurement of the tensile strength and fracture energy of concrete at high strain rates. International Journal of Impact Engineering 32(10):1635-1650

Tedesco JW, Ross CA, Brunair RM (1989) Numerical analysis of dynamic split cylinder tests. Computers \& Structures 32(3):609-624

Tedesco JW, Ross CA, McGill PB, O’Neil BP (1991) Numerical analysis of high strain rate concrete direct tension tests. Computers \& Structures 40(2):313-327

Touchal S, Morestin F, Brunet M (1996) Mesure de champs de déplacements et de déformations par corrélation d'images numériques. In: Actes du colloque National Mécamat, vol 96, pp 179-182

Weerheijm J, Van Doormaal JCAM (2007) Tensile failure of concrete at high loading rates: new test data on strength and fracture energy from instrumented spalling tests. International Journal of Impact Engineering 34(3):609-626

Wu H, Zhang Q, Huang F, Jin Q (2005) Experimental and numerical investigation on the dynamic tensile strength of concrete. International Journal of Impact Engineering 32(14):605-617, fifth International Symposium on Impact Engineering

Yokoyama T, Kishida K (1989) A novel impact three-point bend test method for determining dynamic fracture-initiation toughness. Exp Mech 29:188-194

Zhang QB, Zhao J (2013) Effect of loading rate on fracture toughness and failure micromechanisms in marble. Engineering Fracture Mechanics 102:288-309

Zhao H, Gary G (1996) On the use of SHPB techniques to determine the dynamic behavior of materials in the range of small strains. International Journal of Solids and Structures 33(23):3363-3375 